\title{
JOHN STUART MILL SOBRE EL SUICIDIO
}

\section{Iñigo Álvarez Gálvez ${ }^{1}$}

Resumen: John Stuart Mill no se suicidó, pero pudo haberlo hecho. Si lo hubiera hecho, cuando tenía veinte años (como planeó), nunca habríamos sabido lo que pensaba sobre ello. Pero no lo hizo. Y muchos años después escribió sobre la naturaleza, Dios, la religión y la autonomía. Mi propósito en este artículo es mostrar cómo sus pensamientos sobre la naturaleza y el teísmo afectan de hecho a su postura sobre la autonomía para suicidarse.

Palabras clave: Mill, suicidio, naturaleza, religión, autonomía

\section{John Stuart Mill about suicide}

Abstract: John Stuart Mill didn't take his life; but he could have done it. If he had done it, when he was twenty (as he planned), we would never have known what he thought about it. But he didn't. And many years later he wrote about nature, God, religion and autonomy. My aim in this article is to show how his thoughts about nature and theism affect in fact his stance about autonomy to commit suicide.

Key words: Mill, suicide, nature, religion, autonomy

\section{John Stuart Mill sobre o suicídio}

Resumo: John Stuart Mill não se suicidou, porém pode tê-lo feito. Se o tivesse feito quando tinha vinte anos (como planejou), nunca teríamos sabido o que pensava sobre isso. Porém, não o fez. E muitos anos depois escreveu sobre a natureza, Deus, a religião e a autonomia. Meu propósito neste artigo é mostrar como os seus pensamentos sobre a natureza e o teismo afetam de fato a sua postura sobre a autonomia para suicidar-se.

Palavras-chave: Mill, suicídio, natureza, religião, autonomía

\footnotetext{
${ }^{1}$ Departamento de Filosofía, Facultad de Filosofía y Humanidades, Universidad de Chile, Chile Correspondencia: ialvarezg@uchile.cl
} 


\section{Introducción $^{2}$}

John Stuart Mill no se suicidó 3 . Pero pudo haberlo hecho en 1826. Si hubiera tenido que defender en aquel momento la decisión que no tomó, lo que hubiera dicho entonces habría nacido de las mismas concepciones de base que fueron la fuente de las ideas expresadas muchos años después sobre la naturaleza y el ser humano.

En el presente artículo se quiere mostrar cómo determinadas ideas de Mill sobre la naturaleza (que incluyen sus ideas sobre el origen de esa naturaleza, sobre la religión y sobre la existencia y los atributos de Dios) están enlazadas con, y afectan a, su planteamiento sobre el suicidio. Creo que este planteamiento de Mill es favorable a la permisión del suicidio y creo que esto puede inferirse de algunas de sus afirmaciones contenidas en obras que pertenecen a la misma época de madurez que las referidas a la naturaleza. Por otro lado, el enlace con su crisis emocional puede apoyar mejor la actitud favorable a la que me refiero ${ }^{4}$. Cabe decir, pues, que la aceptación del suicidio por parte de Mill queda mejor sustentada recordando cómo él mismo estuvo cerca de cometerlo.

Las ideas de Mill sobre la naturaleza a las que quiero referirme están contenidas en sus ensayos $\mathrm{La}$ naturaleza, La utilidad de la religión y El teismos. Aunque se trata de tres trabajos escritos en un periodo largo de la vida de Mill, lo cierto es que se puede apreciar en ellos un pensamiento consistente internamente, y consistente también con otras ideas plasmadas en obras tales como El utilitarismo o Sobre la libertad .

\footnotetext{
${ }^{2}$ El presente trabajo se enmarca en el proyecto de investigación titulado "La pregunta por la naturaleza del suicidio" (Fondecyt regular 2014, No 1140721).

${ }^{3}$ Murió en su cama el siete de mayo de 1873 , a resultas de la erisipela contraída apenas cuatro días antes(1:507-508).

4 Con otro sentido, pero no muy lejos de lo que decimos, hay quien, como el reverendo Howowat, relacionó la crisis mental de Mill (y por tanto su plan para suicidarse) con su postura sobre la religión, producto de la educación recibida de su padre(2:184). En cualquier caso, bien se puede decir, como recuerda Berlin(3:132), que la vida de Mill encarnó sus creencias.

5 Aunque en todos los casos aparecerá la misma referencia, las citas del intervalo de las páginas 373 a 402 se refieren al ensayo La naturaleza; las del intervalo 403 a 428 se refieren al ensayo $L a$ utilidad de la religión; y las del intervalo 429 a 489 se refieren al ensayo El teísmo. Una exposición breve de los tres puede verse, por ejemplo, en McCloskey(4:161-173)
}

${ }^{6}$ La muerte de Harriet Taylor, a quien veneraba, no le afectó sin

\section{Las ideas de Mill sobre la naturaleza, Dios y la religión}

Para este autor la naturaleza es amoral, en consecuencia, no cabe deducir de ella planteamientos morales que sirvan de guía a nuestros comportamientos $(7: 377)^{7}$. Es más, si tuviéramos que darle una interpretación moral, tendríamos que decir que lo que vemos a nuestro alrededor es, en muchos casos, lo que correspondería con la voluntad e intención del más cruel, canalla, injusto y perverso de los hombres. De manera que la forma de desarrollarse los acontecimientos no puede ser el modelo a seguir; ni puede ser, mucho menos, interpretado como la obra de un ser bueno y omnipotente, lo que nos abocaría a dejar sin explicación la existencia del mal y, en cambio, nos permitiría justificar sobre esa base todas las atrocidades de los seres humanos 9 . Así pues, de la forma en la que la naturaleza se comporta o de las supuestas intenciones de Dios plasmadas en la naturaleza nada podemos obtener que nos sirva como criterio moral. En este sentido, la religión es una mala consejera. Si algún criterio puede ayudarnos a guiar nuestra vida, ese es el criterio utilitarista de la mayor felicidad; y si alguna religión puede servirnos de faro, esa es la religión utilitarista, verdadera religión de la humanidad, que dirige al ser humano a un perfeccionamiento moral progresivo y constante.

No se puede negar que la religión ha sido tradicionalmente el vehículo de transmisión de la moral, pero no se ve, por otro lado, que ese sea su único fundamento posible. Al contrario, somos muy capaces de entender que la función que en su día tuvo la religión puede no ser ya necesaria(7:430) y que se pueden sostener las verdades y alcanzar

embargo hasta el punto de cambiar su punto de vista sobre estas cuestiones(5:193-195,6:44).

7 "La conformidad con la naturaleza no tiene ninguna conexión con el bien y el mal”, dice más adelante(7:400).

8 "Todo esto — acaba diciendo- lo hace la naturaleza con el más arrogante desprecio por la piedad y la justicia” (7:385).

9 Las palabras de Mill son menos amables: "Ni siquiera la más distorsionada y estrecha teoría del bien que el fanatismo religioso o filosófico pueda formular puede hacer que el gobierno de la naturaleza se parezca a la obra de un ser bueno y omnipotente" (7:389). Y más adelante: "Si la imitación de la voluntad del Creador, tal como se revela en la naturaleza, se tomara como regla para la acción en este caso, las mayores atrocidades de los peores hombres estarían más que justificadas por la evidente intención de la Providencia, que es que en toda la naturaleza animada el fuerte abuse del débil" (7:399). 
similares objetivos sobre otro fundamento distinto al sobrenatural. El progreso ilimitado de nuestra especie, por ejemplo, puede ser un objeto lo suficientemente noble como para hacer de él la meta de nuestra vida(7:420); buscar el bien general, promover la excelencia humana o esforzarse por amar al mundo son objetivos suficientemente grandes como para colmar las aspiraciones de cualquier ser humano y ofrecerle una fuente de felicidad terrenal, eliminando las ansias de una vida ultraterrena $(7: 421)$.

Mill no quiere decir con esto que haya que rechazar de principio toda alusión a lo sobrenatural, pero se trata de un ejercicio de imaginación que solo es aceptable mientras no entre en contradicción con nuestros conocimientos científicos ni nos exija retorcer nuestros sentimientos morales(7:429-430). En particular, solo es aceptable un planteamiento sobrenatural que rechace a un creador omnipotente y conciba la naturaleza y la vida como el resultado de una lucha entre el bien proyectado y la materia ingobernable(7:425). Un planteamiento así nos permite explicar la existencia del mal y nos sitúa en una posición más atractiva, al convertirnos en partícipes de este enfrentamiento y coadyuvantes de Dios(7:425,489). Esta idea, además, no es incompatible con la religión de la humanidad que Mill postula. Se puede tener como meta moral en este mundo el bien general y el progreso de la humanidad y defender al mismo tiempo la posibilidad (pero solo la posibilidad) de que exista un ser benévolo y un plan divino(7:426). Sin duda, algunos necesitan esa esperanza y ese consuelo; pero otros son muy capaces de disfrutar de esta vida terrenal, concibiéndose como parte de una humanidad en continuo progreso, sintiéndose parte en este proceso de mejora y sin ansiar ni necesitar la vida futura(7:427). Esas personas son muy capaces de entender que la verdadera recompensa está en este mundo y que una parte de la vida feliz consiste en que esta se termine cuando se ha disfrutado larga e intensamente de los placeres que pueda ofrecer, y cuando ya nada quede que "estimule la curiosidad y mantenga el deseo de prolongar la existencia” (7:428).

Me parece que esta idea es perfectamente compatible con una posición favorable al suicidio. En definitiva, lo que Mill nos dice es que parte de la felicidad propia consiste en que mi vida finalice cuando nada quede por desear. Puede entenderse que eso sucede cuando la vida ha sido larga y uno ha gozado suficientemente de ella, pero cabe también pensar que ese momento depende, en buena medida, de la particular visión que uno mismo tenga de su vida; y no es descabellado considerar entonces que ese momento final puede ser buscado de propósito como el último elemento de una vida feliz.

Frente a ello, ningún planteamiento religioso que pueda ser base de un argumento contrario al suicidio parece tener fuerza suficiente. Los planteamientos teístas que defienden la existencia de varios dioses o la de un dios voluble quedan eliminados, pues chocan con la idea de que el mundo obedece a leyes generales(7:432-433). De entre los que pueden asumir esa idea hay que desechar los que se basan en el consenso general de la humanidad (que ni existe ni aunque existiera serviría de fundamento)(7:442); los que se basan en la percepción clara de nuestra conciencia (sobre la que no se puede construir ningún conocimiento) (7:444); y los que postulan de manera apriorística la mente de Dios como causa primera de todo lo que hay (pues ni es cierto que todo tenga una causa - la energía parece no tenerla - ni es necesario acudir a una explicación tal cuando pueden bastarnos otras explicaciones naturales)(7:437-439).

En definitiva, el único argumento admisible (por su carácter empírico e inductivo) es el referido al plan divino: así como encontramos trazas de un plan en las cosas hechas por los seres humanos, así podemos encontrar trazas similares en el orden de la naturaleza, de lo cual inferimos que hay alguien que ha tenido el propósito de hacer esto. La analogía es desde luego débil, y en el mejor de los casos solo se puede afirmar que el hecho de que exista un planificador es más probable que el hecho contrario (que no deja de ser posible) $(7: 449,450)$. No es poco, pero no es por cierto una certeza.

En todo caso, aun aceptando esta conclusión queda por ver qué tipo de planificador es ese que tal vez exista. Parece sensato pensar que una posición contraria al suicidio que enlaza de algún modo con la voluntad de Dios debe sostenerse sobre la base de unos atributos divinos adecuados. Y tampoco en este punto es fácil de mantener la postura tradicional. Si, como se ha dicho, el argumento 
del plan es el único defendible, no es posible afirmar ni la omnipotencia divina (pues quien es omnipotente no necesita plan alguno) ni la omnisciencia (pues los notorios defectos en el diseño de la naturaleza no se concilian bien con un creador infinitamente sabio)(7:451-453). De manera que, en conclusión, hay que pensar que Dios posee un poder limitado y no puede (porque el material con el que trabaja no se lo permite, por ejemplo), o no sabe realizar su plan de mejor modo(7:455).

Pero, aceptado esto, ¿acaso sabemos con qué intención trazó su plan en relación con nosotros? Por lo que conocemos, tal vez podamos decir que quiso que lo creado tuviera cierta duración, pero de esto nada podemos inferir respecto de su disposición para con las criaturas racionales(7:457). Tal vez su propósito fue benevolente y quiso nuestra felicidad, si bien es evidente que ese no pudo ser su único propósito, visto el sufrimiento que nos rodea $(7: 458)^{10}$. Y lo mismo puede decirse de la justicia divina, de la que no hay prueba alguna en la naturaleza(7:459).

En resumen, desde la teología natural podemos concluir que, en el supuesto de que exista Dios, se trata de un ser con un poder muy grande, pero limitado (sin que podamos decir a qué obedece esa limitación); con una inteligencia enorme, pero quizás también limitada; y que desea, o está de acuerdo con, la felicidad de sus criaturas, pero que parece haber tenido otros motivos para actuar, no siendo aquélla, por tanto, su única finalidad. Todo lo que vaya más allá de esto no será sino producto de nuestros propios anhelos y deseos(7:459).

Y llegamos al punto que nos interesa. Concebido un Dios así, cabe preguntarse también qué tipo de seres ha hecho; en particular, con qué atributos ha creado a los seres humanos y si les ha concedido la propiedad de la inmortalidad. Desde luego, nuestra experiencia nos indica que la muerte del organismo supone el cese de la actividad men$\operatorname{tal}(7: 461)$. Pero nuestra experiencia tiene un límite y más allá de él cabe imaginar que un ser divino

\footnotetext{
10 "Pero dar un salto de aquí —dice Mill- (de la consideración de la benevolencia como uno de los atributos morales de Dios) a la inferencia de que sus únicos o principales propósitos son los de la benevolencia y que su único fin y objetivo es la felicidad de sus criaturas, no sólo no está justificado con ninguna prueba, sino que es una conclusión que se opone a todas las pruebas que tenemos"(7:458).
}

de un poder limitado y relativamente benévolo nos haya concedido la inmortalidad $(7: 466)^{11}$.

Este es el planteamiento de Mill sobre la naturaleza y sobre la existencia de Dios, sus atributos, la inmortalidad y la revelación. Es claro que Mill desea situarse en una postura escéptica o agnóstica, que le impide afirmar algo definitivo más allá del límite de la ciencia y negar tan solo aquello que parece ser incompatible con ella (la omnipotencia, la omnisciencia). Todo lo más que se puede afirmar es que no sabemos si existe un creador; que, en todo caso, se trataría del creador del orden, pero no del universo (la materia y la energía parece que se escapan a esta creación); que posee un poder limitado y tiene una benevolencia relativa; y que quizá, pero solo quizá, ha tenido a bien concederos la inmortalidad(7:482). De manera que, dice Mill, "toda la esfera de lo sobrenatural pasa del ámbito de la creencia al ámbito de la simple esperanza" (7:483).

Podemos tener la esperanza de que las cosas sean así (lo que no es una cuestión menor). El ser humano, sometido como está a privaciones y miserias inevitables en una vida corta y limitada, necesita ampliar sus aspiraciones y la idea de su destino(7:483). Y no es una insensatez dejar que la imaginación se desarrolle y dé satisfacción a ese anhelo, aprovechando los campos que la ciencia no puede roturar, para tomar en consideración otros elementos diferentes que nos permiten construir una vida amable y atractiva(7:485). Y si la razón es necesaria para saber, la imaginación puede serlo para vivir $^{12}$, para el religioso y también para el escéptico, que puede fortalecer con ella esa religión de la humanidad, que es la religión del deber moral configurada por el utilitarismo $(7: 488)$.

Lo que debe ser destacado de todo esto no es solo el hecho de que estas conclusiones queden relega-

\footnotetext{
${ }^{11}$ Lo más difícil es sostener una idea así sobre la base de la revelación divina mediante milagros. Las pruebas con las que contamos al respecto son escasas y débiles(7:470). No tenemos experiencia directa de tales sucesos sobrenaturales, y la prueba testimonial que se aduce es tremendamente fragmentaria e imperfecta(7:478). Lo que podemos afirmar, de acuerdo con la ciencia, por el contrario, es que los eventos de este mundo se producen por causas naturales y que el gobierno de Dios, de existir, responde también a esas causas.

${ }^{12}$ Para Millar, en este punto Mill va demasiado lejos. Plantear esta esperanza tal como lo hace Mill, dice Millar, cuando no hay razón para pensar en esa posibilidad de lo sobrenatural, no encaja de manera coherente con lo afirmado a lo largo de todo el ensayo(8:198-199).
} 
das al ámbito de la imaginación (y vean debilitado su impacto en la vida de los seres humanos), sino también el que, sea cual sea la influencia que tengan, esta no llega al punto de permitir que sobre ellas se constituya el deber moral. Con esas ideas en la mente uno puede sentir que el cumplimiento de su deber sirve de ayuda al plan de Dios para hacer que triunfe el bien sobre el mal, pero eso no le permite concluir que ese bien depende de la voluntad de Dios. En términos más concisos: el bien se configura de acuerdo con el principio utilitarista. Y ese criterio es el único que permite llegar a una conclusión moral acerca del suicidio.

\section{Sobre el suicidio de Mill y Mill sobre el suicidio}

En el otoño de 1826 Mill pasa por una profunda crisis emocional (5:139). Sin alicientes y persuadido de que su amor por la mejora del género humano había desaparecido, va sintiéndose cada día más apesadumbrado y acaba concibiendo la idea del suicidio ${ }^{13}$. No sabemos qué habría pasado si no hubieran llegado a sus manos las Memorias de Marmontel ${ }^{14}$. En cualquier caso, interesa destacar ahora el hecho de que la idea del suicidio no le era ajena. Es verdad que en la Autobiografía no afirma que sea la mejor opción en cualquier situación dada o que baste con haberlo decidido para considerarlo aceptable, pero no es menos cierto que tampoco dice que se trate de una conducta reprochable en sí misma y que se deba evitar ${ }^{15}$. El hecho de darse muerte a uno mismo no parece que merezca, por sí, ningún juicio negativo, ni religioso ni moral (que es de suponer que habría aflorado si él se hubiera sentido arrepentido de aquella decisión o si hubiera pensado que era, en el fondo, inmoral o pecaminosa). Esta actitud puede enlazarse con lo planteado en el ensayo Sobre la libertad ${ }^{16}$.

\footnotetext{
13 "Frecuentemente me preguntaba — dice - si podía o si tenía que seguir viviendo, cuando la vida iba a transcurrir de este modo. Usualmente me contestaba que no creía que pudiera soportarlo más de un año" (5:145).

${ }^{14}$ La lectura del pasaje al que Mill se refiere(9:93-94) le hace llorar y le permite darse cuenta de que todavía hay en él sentimientos dignos de consideración. A partir de entonces comienza una recuperación paulatina y también, por lo demás, una cierta desviación doctrinal. Una interesante interpretación de la crisis y su superación desde un punto de vista psicoanalítico puede verse en Mazlish(10:205-230).

${ }^{15}$ Lo mismo podemos inferir de otros fragmentos (por ejemplo, en su Diario) en los que aparece la misma idea suicida(6:44).

${ }^{16}$ Las citas referidas al intervalo de páginas 5 a 128 corresponden a la obra Sobre la libertad y las referidas al intervalo 129 a 201 corresponden a El utilitarismo.
}

En esta obra Mill defiende la necesidad de limitar el poder de la sociedad sobre el individuo, de impedir la tiranía de la mayoría, que lo agobia y le impide desarrollar su carácter original, encauzando y sometiendo su conducta de acuerdo con las formas particulares de ver las cosas que tienen aquellos que dirigen la sociedad(11:9-11) ${ }^{17}$. Lo que se pregunta Mill es hasta qué punto es admisible esta intromisión y este control. La respuesta es sobradamente conocida: "El único fin por el cual la humanidad está justificada, individual o colectivamente, para interferir en la libertad de acción de alguno de sus miembros es la propia protección. (...) La única finalidad por la que el poder puede ser ejercido legítimamente sobre un miembro de una comunidad civilizada, contra su voluntad, es la prevención del daño a otros. Su propio bien, físico o moral, no es justificación suficiente. No puede ser legítimamente forzado a hacer o abstenerse de hacer porque eso será lo mejor para él, porque eso le hará más feliz, porque, en la opinión de otros, eso sería más sabio, o incluso correcto. Esas son buenas razones para discutir con él, razonar con él, convencerlo o suplicarle, pero no para obligarle o para infligirle un mal si hace otra cosa. Para justificar eso, debe considerarse que la conducta de la que se le desea disuadir produce mal alguien. La única parte de la conducta de cualquier persona por la que es responsable ante la sociedad es la que tiene que ver con otros. En la parte que le concierne a él mismo, su independencia es, de derecho, absoluta. Sobre sí mismo, sobre su propio cuerpo y mente, el individuo es soberano"(11, p. 14). Merece la pena esta larga cita porque ella contiene la idea nuclear que nos interesa destacar, a saber, que los individuos poseen un ámbito de libertad cerrado a la compulsión social (del tipo que sea) constituido por todos aquellos comportamientos que solo le afectan a él y no perjudican a los demás.

Conviene llamar la atención sobre varios puntos. Para empezar, esta afirmación está dirigida a los individuos adultos de sociedades que han llegado a un determinado estado de civilización(11:14-15), lo que viene a sugerir, como afirma Gray(12:198), que la autarquía es condición necesaria de la autonomía.

\footnotetext{
17 "Todo lo que da algún valor a nuestra existencia — afirmadepende de la restricción impuesta a las acciones de los demás”(11:9).
} 
Por otro lado, lo que queda proscrito es la compulsión, la coerción, el control mediante sanciones. Cabe discutir, aconsejar o suplicar, mas no obligar. Bien es cierto que la frontera entre lo que pueda ser una súplica y una orden es sutil en la práctica, pero al menos en la teoría puede marcarse con cierta precisión: si creemos que la conducta del individuo merece sanción, lo que hagamos para evitar que la realice podrá ser calificado de instrumento de compulsión; si, por el contrario, creemos que el individuo es libre de actuar como quiera, lo que hagamos para convencerle de que actúe de otro modo podrá ser calificado de instrumento de persuasión, pero no de control. Cuando en El utilitarismo se refiere a la moral y a la simple conveniencia(11:184), distingue una de otra por el hecho de que solo en la primera se trata de deberes. Hay cosas, afirma, que nos gustaría que la gente hiciera, pero que sabemos que no está obligada a hacer; y, en consecuencia, aceptamos que no merecen un castigo si no lo hacen(11:184). En Sobre la libertad habla precisamente de esas cosas, de esos comportamientos que quizá nos gustaría que otro siguiera, pero que no podemos controlar con sanciones, porque ningún individuo debe nada a la sociedad en aquellas cosas que le atañen solo a él ${ }^{18}$.

Por supuesto, podemos pensar que todo lo que hace un individuo afecta de una u otra forma a la sociedad. Pero no es menos cierto que hay comportamientos que solo de una manera indirecta y amplia se puede decir que afectan a otros; comportamientos cuyos efectos directos y primarios se circunscriben al individuo que los realiza $(11: 16)^{19}$. Respecto de ellos se configura ese ámbito de libertad en el que es el individuo el que decide, sin verse compelido por las sanciones sociales, ni siquiera aunque esa compulsión consiguiera que fuera más

\footnotetext{
${ }^{18}$ Mill no deja el asunto claramente delimitado. El individuo no merece sanción por los actos que solo a él conciernen, pero - diceeso no es óbice para considerarlo como loco, inferior, rehuirlo o marginarlo(11:85-86). Esas son consecuencias naturales de su hacer libre y del hacer libre de los demás, y no un verdadero castigo(11:86). $\mathrm{Si}$, como afirma Ryan, calificar una acción como incorrecta supone admitir que es socialmente dañosa(13:166), entonces habría que decir que la acción de ese individuo no es incorrecta. Pero quizá saber eso no le sirva de mucho, pues no se ve con claridad cuál pueda ser la diferencia en relación con la coerción que esa persona puede sentir.

${ }^{19}$ En este sentido, podemos distinguir, como sugiere Rees, entre los comportamientos que afectan, sin más, a otros y los comportamientos que afectan a los intereses de otros(14:180).
}

feliz. Es sorprendente que esto lo afirme un utilitarista, pues cabría pensar que lo que debemos procurar por encima de todo es la maximización de la felicidad. Si queremos mantenernos dentro del utilitarismo (como creo que debemos hacer), sostener que no hay que aumentar la felicidad del individuo solo es posible si concebimos algún tipo de compensación por otro lado. En otros términos, el hecho de permitir que la esfera privada de un individuo sea controlada produciría tal disminución de felicidad (a él y sobre todo en términos generales) que es perfectamente razonable rechazar lo primero en nombre, precisamente, de la felicidad: la mayor felicidad se alcanza cuando se permite que las personas hagan su voluntad mientras no perjudiquen a otros, aunque, en nuestra opinión, se hagan a sí mismos más infelices ${ }^{20}$.

Ese ámbito de libertad permite reunirnos o asociarnos con quienes queramos, sentir y pensar lo que queramos, $y$, por lo que nos interesa en este momento, diseñar nuestra vida como queramos. Las palabras de Mill son claras: tenemos libertad para "diseñar el plan de nuestra vida que encaje con nuestro carácter; de hacer lo que queramos ateniéndonos a las consecuencias; sin impedimentos de nuestro prójimo en tanto lo que hacemos no le perjudique, aunque puedan pensar que nuestra conducta es estúpida, depravada o incorrecta" (11:17).

Bastarían estas ideas para inferir de aquí una posición favorable al suicidio: si puedo pensar como yo quiera en asuntos de moral y religión, y si puedo trazar mi propio plan de vida, parece obvio que puedo decidir cómo vivir y en qué momento poner fin a mi existencia, con independencia de lo que opinen o quieran los demás (siempre y cuando no les cause con ello ningún perjuicio). Pero, por si esto no fuera suficiente, en las páginas siguientes Mill se explaya sobre la libertad de pensamiento, que es precisamente la que está en juego

\footnotetext{
20 "Gana más la humanidad — afirma — tolerando que cada cual viva como cree que es mejor para él, que obligando a cada cual a vivir como le parece mejor al resto"(11:17). Para Mill, buena parte de la felicidad y del desarrollo cabal de una persona se cifra en atender a los requerimientos de su propia naturaleza, como recuerdan Gray(12:201), Skorupski(15:348,357) y Donner(16:231), de manera que la sociedad es más feliz (he ahí la ganancia) porque sus miembros son más felices. Pero también gana la sociedad (y la humanidad) porque el progreso social y económico depende a la postre de esa individualidad(17;233,18:223).
} 
en el suicidio. Porque, en efecto, el suicidio no se relaciona con el derecho a la vida, que me permite atajar la pretensión de otros de quitarme la vida contra mi voluntad, pero que nada dice acerca de mi voluntad de quitarme la vida. Desde luego, si no pudiera quitármela nos veríamos obligados a sostener que hay un deber de vivir (en vez de un derecho a la vida, que es lo que hay). Pero si lo que queremos es sostener, además, que la decisión de no vivir esté protegida de la intromisión de otros, entonces debemos buscar un derecho que me permita precisamente hacer tal cosa. Ese es el derecho al pensamiento libre; que no se puede circunscribir solo al ámbito de la mente (cuya libertad no precisa ser protegida con un derecho), sino que únicamente tiene sentido si se refiere a los comportamientos que son la plasmación de tal pensamiento en palabras o en obras. Esta es la idea que expresa Mill cuando enlaza la libertad de pensar y la libertad de trazar nuestros planes de $\operatorname{vida}(11: 16-17)$.

El planteamiento es claro: las opiniones y las acciones de un individuo pueden ser limitadas y controladas cuando perjudican a los demás, "pero si se abstiene de molestar a otros en lo que les concierne, y simplemente actúa de acuerdo a su propia inclinación y juicio en cosas que le conciernen sólo a él, las mismas razones que indican que la opinión debe ser libre, prueban también que a esa persona se le debe permitir, sin importunarle, que ponga en práctica sus opiniones por su cuenta y riesgo" (11:62-63). Desde luego, no todos los comportamientos son igualmente valiosos, pero con independencia de eso lo valioso es el desarrollo de la propia capacidad de discernimiento, el fortalecimiento de la capacidad de pensar, de razonar, de decidir, en función de lo que uno es $(11: 65)^{21}$. Eso es lo importante y lo que debe ser protegido; incluso aunque, en un caso determinado, pensemos que la persona se equivoca al actuar así: "Lo que importa —asegura - no es sólo lo que los hombres hacen, sino también qué tipos de hombres son los que lo hacen" (11:66). Y lo que la humanidad pierde con hombres que imitan a otros, lo gana

\footnotetext{
${ }^{21}$ Skorupski se refiere a lo mismo cuando afirma que Mill acepta que las personas tengan diferentes ideales acordes con sus diferentes formas de vida, a la vez que propone determinados ideales de vida, lo cual — dice — no es incompatible. "Lo incompatible — concluyesería prescribirlos a los que no los comparten, salvo sobre la base de la utilidad"(15:362).
}

con hombres que son capaces de poner en funcionamiento sus capacidades para observar, comparar, prever y decidir por sí mismos. Los primeros son los hombres empequeńecidos, los hombres mediocres de los que habla Ingenieros(19:40), o los hombres masa, que no se diferencian de otros hombres, de los que habla Ortega $(20: 49)^{22}$. Los segundos son los que expresan la condición deseable de la naturaleza humana; los que son capaces de producir ideas y sentimientos originales, es decir, nacidos de sí mismos ${ }^{23}$. Esos son los individuos valiosos y dignos; que lo son cuales sean esas ideas y sentimientos originales ${ }^{24}$. Cosa diferente es que haya que limitarlos cuando y porque perjudican a los demás, y precisamente porque impiden que los demás puedan desarrollar sus propias capacidades. Pero no siendo ese el caso, la limitación solo "opaca y embota" la naturaleza humana(11:70). La individualidad es uno de los elementos del bienestar humano y las medidas que la reducen y aplastan se convierten en medidas despóticas, cuales sean las razones por las que se toman(11:71). Por el contrario, permitir que la individualidad de cada cual se desarrolle libremente genera seres humanos útiles y sociedades felices; sociedades que pueden contar con individuos desarrollados, fuertes y libres, que son la fuente de las mejoras, y seres humanos que pueden dar a la sociedad lo mejor que tienen de sí mismos, que es su propio modo de vivir. Si se acaba con la libertad, pues, se acaba con el único lugar de donde pueden surgir las mejoras sociales y el progreso $(11: 78)^{25}$.

No se refiere Mill aquí de manera explícita al suicidio, pero era importante destacar esta defensa absoluta de la libertad de acción, de la capacidad

\footnotetext{
${ }^{22}$ Para Skorupski(15:354), el planteamiento de Mill es, desde luego, contrario al autoritarismo, pero no es, en absoluto, contrario al elitismo. Donner(16:233), en cambio, advierte algunos elementos que inclinarían la postura de Mill hacia el igualitarismo radical.

$23 \mathrm{Y}$, por tanto, imputables a ellos. Lo que le preocupa fundamentalmente a Mill, dice $\operatorname{Smith}(21: 247)$ en este sentido, es mostrar cómo la libertad está enlazada a la responsabilidad por los propios deseos y acciones.

24 Que pueden ser, como sugiere Clor(18:215), ciertamente reprobables. Tal vez, dice Clor, Mill tenga un concepto demasiado optimista de la naturaleza humana y de lo que un ser humano libre puede hacer de manera espontánea(18:216).

${ }^{25}$ Arneson(22:263) apunta a lo mismo cuando indica que "incluso en los casos extremos en los que los individuos eligen voluntariamente algo catastrófico para ellos, la intervención (paternalista) debilitará el clima general de libertad que sabemos que es tan difícil de mantener como necesario es para los seres humanos florecer".
} 
para desarrollar la vida como uno quiera, porque tamaña amplitud nos inclina a pensar que abarca también el momento y el modo de poner fin a la vida. Mill asegura que "si una persona tiene una cantidad aceptable de sentido común y experiencia, su propio modo de disponer su existencia es el mejor, no porque sea el mejor en sí mismo, sino porque es su propio modo"(11:75); insiste después en que "ninguna persona ni ningún conjunto de personas están justificados a decirle a otra criatura humana de edad adulta que no debe hacer con su vida por su propio beneficio lo que ha elegido hacer con ella"(11:84). No se ve la razón para excluir de estas decisiones el modo en el que la propia existencia llega a su fin.

Aun si afecte a otros; mientras no se produzca un daño cierto (o exista riesgo de ello), se trata de un inconveniente que la sociedad debe soportar por el bien de la libertad(11:91). Es cierto que la distinción no es precisa, y probablemente Gray tiene razón cuando afirma que la concepción de los intereses humanos y del daño que tiene Mill es tan vaga que impide saber de qué manera se aplica su principio y en definitiva lo hace inútil $(23: X I X)^{26}$. Pero, con todo y con eso, nos basta para nuestros fines saber que para Mill hay un ámbito inexpugnable. Es posible que no podamos saber con exactitud qué pensaba Mill que afectaba a los intereses de otros o les causaba daño, pero sabemos que pensaba que había casos en los que eso no se producía $^{27}$. Lo que interesa dilucidar es si el suicidio es uno de ellos.

Podemos preguntarnos entonces si el planteamiento de Mill tiene algún límite que impida incluir el suicidio en ese conjunto ${ }^{28}$. Creo que los únicos límites que Mill establece están implícitos en la misma formulación del principio. Esto viene al caso de una observación que hace acerca de la esclavitud, de acuerdo con la cual uno no puede usar

\footnotetext{
26 Lo mismo reconocen, por ejemplo, Skorupski(15:342), Smith(21:240), Clor(18:208) y $\operatorname{Rees(14:183),~aunque~eso~no~le~}$ impide a este último defender el principio.

${ }^{27}$ En un sentido similar, dice Rees que es falso suponer (como hacen los críticos) que la validez del principio de Mill dependa de que existan comportamientos que no afectan a la sociedad(14:172). Puede que no existan comportamientos que, de un modo u otro, afecten a alguien, pero para Rees es claro que hay casos en los que los intereses de otros no se ven afectados, que es a lo que apunta Mill(14:174).

${ }^{28}$ Como podría ser un planteamiento perfeccionista de la naturaleza o de la vida humanas. Creo que tiene razón $\operatorname{Gray}(12: 208-210)$ al negar esa interpretación.
}

su libertad para entregarse como esclavo porque estaría eliminando su libertad. En sus palabras: “El principio de libertad no puede requerir que uno pueda ser libre de no ser libre. No es libertad que se le permita alienar su libertad"(11:114). Podría pensarse que si uno no puede entregarse como esclavo usando su libertad, mucho menos podría quitarse la vida, pues también en este caso se emplea la libertad para eliminar la libertad. Entiendo, no obstante, que hay una diferencia sensible entre ambos supuestos. Lo que Mill hace en Sobre la libertad es establecer una norma: "Cada cual debe poder decidir libremente en aquellas cosas que sólo le afectan a él". Como eso se presenta como una norma, va de suyo que pretende ser impuesta con independencia de la voluntad de los destinatarios. Así es como deben ser las cosas. Y si esto es así, no cabe entonces que sea válido que yo, destinatario de la norma, anule la norma con mi voluntad, vendiéndome como esclavo. Cosa distinta es que yo no pueda decidir hacer siempre lo que quiera otro. En principio, mi conducta no se diferenciará de la del esclavo; pero si en un momento dado el esclavo y yo queremos hacer nuestra voluntad, él no podrá y yo sí. Es decir, para mí sigue existiendo la norma (puedes hacer lo que quieras) mientras que para el esclavo la norma dejó de existir (que es lo que no puede suceder). En otras palabras, uno no puede convertirse en esclavo (desde el punto de vista normativo) sin anular la norma, pero puede comportarse como esclavo, usando precisamente la libertad que la norma le concede.

Y en el mismo sentido se puede decir que el destinatario puede, sin anular la norma, poner las condiciones para limitar su aplicación o incluso hacerla inaplicable. Por ejemplo, respecto del derecho de reunión, puedo escapar a una isla desierta con víveres suficientes para el resto de mi vida y quemar la nave. Nunca más podré reunirme con otros seres humanos. Pero eso no significa que anulé la norma. Lo que he hecho es poner las condiciones para que no pueda ser aplicada, que es cosa diferente.

Así ocurre también con el suicidio. Al quitarse la vida, el destinatario de la norma no anula la norma que protege su libertad (que es lo que no puede hacer); lo que hace es poner las condiciones para que no pueda ser aplicada ${ }^{29}$.

${ }^{29}$ Queda al margen de este planteamiento la discusión sobre si la 
Esta es la posición que, según entiendo, plantea Mill acerca del suicidio. Y creo que esta postura favorable al suicidio está enlazada al planteamiento que ofrece sobre la naturaleza en general, sobre la naturaleza humana en particular y sobre la existencia de Dios y la inmortalidad. Me parece que la propuesta sobre la libertad y - por lo que a nosotros nos interesa- sobre el suicidio sería muy diferente si la conclusión acerca de las otras materias hubiera sido la de que en efecto existe Dios, autor de la ley moral, que interviene en el acontecer humano y que nos ha transmitido un determinado mensaje a través de la revelación; la propuesta habría sido muy diferente si hubiera llegado a la conclusión de que tenemos un alma inmortal y, por tanto, de que nuestra existencia continúa más allá de este mundo. Pero, por el contrario, lo que piensa es que no podemos afirmar que la naturaleza esté sometida a las órdenes de Dios ni que nosotros le debamos obediencia. Podemos hacer un ejercicio de imaginación y suponer la existencia de Dios, en la medida en que no es incompatible con lo que la ciencia establece, pero eso significa también que no hay base suficiente para afirmarlo como conocimiento y que, en consecuencia, no podemos ofrecerlo como base de una moral utilitarista. Y es aquí donde se enlaza el planteamiento sobre la libertad. Al margen de esta postura teísta, que se sitúa en el campo de lo posible, se puede defender la libertad absoluta sobre todo aquello que afecta al propio agente y no dańa a los demás. Sea cual sea el concepto de daño al que Mill se refiere, parece que el hecho de quitarse la vida (si no causa daño a otros) es una plasmación de esta libertad.

libertad que Mill pretende proteger es la que corresponde a los individuos preocupados (y capaces) de progresar y de mejorar sus capacidades. Véase al respecto $\operatorname{Smith}(21: 257-258)$. Sea lo que sea de esto, cabe concebir el suicidio como el punto final de ese progreso $y$ desarrollo de las capacidades individuales.
Difícilmente se hubiera podido defender esta idea si se hubiera partido de una postura diferente, es decir, religiosa, acerca de la naturaleza y de la naturaleza humana.

La naturaleza nada tiene que ver con la moral; y presentarla como criterio para dirigir nuestras conductas y valorar nuestros comportamientos es plantear algo irracional (porque nuestros esfuerzos se dirigen precisamente a separarnos de la naturaleza) y algo inmoral (porque lo que vemos en la naturaleza es justamente lo que repudiamos desde el punto de vista moral). En definitiva, en el terreno moral lo que hay que preguntarse no es ¿cómo actuaría la naturaleza en este caso? sino ¿cuánta felicidad general se produce con este acto? 
John Stuart Mill sobre el suicidio - Iñigo Álvarez Gálvez

\section{Referencias}

1. Packe MSJ. The Life of John Stuart Mill. New York: The MacMillan Company; 1954.

2. Stack D. The Death of John Stuart Mill. The Historical Journal 2011; 54(1): 167-190.

3. Berlin I. John Stuart Mill and the Ends of Life. In: Gray J, Smith GW, (eds.) J. S. Mill On Liberty in Focus. London: Routledge; 1991: 131-161.

4. McCloskey HJ. John Stuart Mill: A Critical Study. London: MacMillan and Co.; 1971.

5. Mill JS. Autobiography. In: Robson JM, Stillinger J, (eds.) The Collected Works of John Stuart Mill, vol. I, Autobiography and Literary Essays. Toronto: University of Toronto Press; 1981: 1-290.

6. Mill JS. Diario. Madrid: Alianza Editorial; 1996.

7. Mill JS. Three Essays on Religion. In: Robson JM, (ed.) The Collected Works of John Stuart Mill, vol. X, Essays on Ethics, Religion and Society. Toronto: University of Toronto Press; 1985: 369-489.

8. Millar A. Mill on Religion. In: Skorupski J, (ed.) The Cambridge Companion to Mill. Cambridge: Cambridge University Press; 1998: 176-202.

9. Marmontel JF. Mémoires. Paris: Mercure de France; 1999.

10. Mazlish B. James and John Stuart Mill. Father and Son in the Nineteenth Century. New York: Basic Books; 1975.

11. Mill JS. On Liberty and Other Essays. Oxford: Oxford University Press; 1991.

12. Gray J. Mill's Conception of Happiness and the Theory of Individuality. In: Gray J, Smith GW, (eds.) J. S. Mill On Liberty in Focus. London: Routledge; 1991: 190-211.

13. Ryan A. John Stuart Mill's Art of Living. In: Gray J, Smith GW, (eds.) J. S. Mill On Liberty in Focus. London: Routledge; 1991: 162-168.

14. Rees JC. A Re-reading of Mill On Liberty. In: Gray J, Smith GW, (eds.= J. S. Mill On Liberty in Focus. London: Routledge; 1991: 169-189.

15. Skorupski J. John Stuart Mill. London: Routledge; 1989.

16. Donner W. Mill on Liberty of Self-development. In: Smith GW, (ed.) John Stuart Mill's Social and Political Thought, Critical Assessments. London: Routledge; 1998; 228-237.

17. Wilson F. Mill on Psychology and the Moral Sciences. In: Skorupski J, (ed.) The Cambridge Companion to Mill. Cambridge: Cambridge University Press; 1998: 203-254.

18. Clor HM. Mill and Millians on Liberty and Moral Character. In: Smith GW, (ed.) John Stuart Mill's Social and Political Thought, Critical Assessments. London: Routledge; 1998: 207-227.

19. Ingenieros J. El hombre mediocre. Barcelona: Brontes; 2013.

20. Ortega y Gasset J. La rebelión de las masas. Madrid: Espasa-Calpe; 1993.

21. Smith GW. Social Liberty and Free Agency. In: Gray J, Smith GW, (eds.) J. S. Mill On Liberty in Focus. London: Routledge; 1991: 239-259.

22. Arneson R.J. Mill versus Paternalism. In: Smith GW, (ed.) John Stuart Mill's Social and Political Thought, Critical Assessments. London: Routledge; 1998: 253-272.

23. Gray J. Introduction. In: Mill JS. On Liberty and Other Essays. Oxford: Oxford University Press; 1991: VII-XXXV.

Recibido: 5 de diciembre de 2014

Aceptado: 29 de enero de 2015 